OPEN ACCESS

Edited by:

Pasqualina Woodrow, University of Campania Luigi Vanvitelli,

Italy

Reviewed by:

Bilquees Gul,

University of Karachi, Pakistan

Abdul Hameed,

University of Karachi, Pakistan

Ming Cong,

Yantai University, China

${ }^{*}$ Correspondence:

Jinbiao Ma

majinbiao@ms.xjb.ac.cn

Lei Wang

egiwang@ms.xjb.ac.cn

Specialty section:

This article was submitted to

Plant Abiotic Stress,

a section of the journal

Frontiers in Plant Science

Received: 18 November 2020

Accepted: 22 March 2021

Published: 12 April 2021

Citation:

Zhang $H$, Hu M, Ma H, Jiang L,

Zhao Z, Ma J and Wang L (2021)

Differential Responses of Dimorphic

Seeds and Seedlings to Abiotic

Stresses in the Halophyte Suaeda

salsa. Front. Plant Sci. 12:630338.

doi: $10.3389 / f p / s .2021 .630338$

\section{Differential Responses of Dimorphic Seeds and Seedlings to Abiotic Stresses in the Halophyte Suaeda salsa}

\author{
Hao Zhang',2, Mingfang Hu', Hongyuan Ma ${ }^{3}$, Li Jiang', Zhenyong Zhao ${ }^{1,2}$, Jinbiao Ma ${ }^{1 *}$ \\ and Lei Wang ${ }^{1,2 *}$
}

1 State Key Laboratory of Desert and Oasis Ecology, Xinjiang Institute of Ecology and Geography, Chinese Academy of Sciences, Urumqi, China, ${ }^{2}$ University of Chinese Academy of Sciences, Beijing, China, ${ }^{3}$ Northeast Institute of Geography and Agroecology, Chinese Academy of Sciences, Changchun, China

The period between seed germination and seedling establishment is one of the most vulnerable stages in the life cycle of annuals in the saline environments. Although germination characteristics of Suaeda salsa seeds have been reported, the comparative germination patterns of dimorphic seeds and seedling growth to different abiotic stresses remain poorly understood. In this study, germination responses of dimorphic seeds to light and temperature were compared. Meanwhile, responses of dimorphic seeds and thereafter seedlings of $S$. salsa to different concentrations of $\mathrm{NaCl}$ and $\mathrm{Na}_{2} \mathrm{SO}_{4}$ were also tested. The results showed that the light did not significantly affect germination percentage of brown seeds, but significantly promoted germination of black seeds. Brown seeds could reach high germination percentage over a wide temperature range, however, germination of black seeds gradually increased with the increase of temperature. Brown seeds had higher germination percentage and velocity than black seeds under the same salt conditions. However, black seeds had higher recovery germination than brown seeds when transferred to deionized water. Young seedlings had lower salt tolerance than germinating seeds. At the same concentrations, $\mathrm{Na}_{2} \mathrm{SO}_{4}$ had stronger inhibitory effect on seed germination and seedling growth than $\mathrm{NaCl}$. This study comprehensively compared germination traits of dimorphic seeds and seedling growth of $S$. salsa, and then developed a conceptual model to explain their adaptation to harsh saline environment.

Keywords: germination index, halophyte, salt stress, seed heteromorphism, seedling growth, Suaeda salsa

\section{INTRODUCTION}

Suaeda salsa, an annual halophyte, grows in saline and alkaline soils on lake shores and beaches of Asia and Europe (Zhu et al., 2003). This plant can accumulate high amount of salt in aboveground parts (Zhao, 1991; Wang et al., 2020). S. salsa has been studied for its potential in phytoremediation of saline soils and as gourmet vegetable, edible oil, and animal feed (Song and Wang, 2015; Shang et al., 2020). The fresh leaves of $S$. salsa, traditionally used as vegetable, have high nutritional 
value. The contents of protein, crude fiber, and vitamin $\mathrm{C}$ in fresh branches are $2.3,63.7$, and $13 \mathrm{mg} \mathrm{kg}^{-1}$, respectively. The dry seeds of $S$. salsa contain ca. $20 \%$ edible oil and the unsaturated fatty acids account for $>90 \%$. Furthermore, S. salsa is a promising model plant to study salt tolerance (Song and Wang, 2015).

Suaeda salsa produces two types of seeds on a single plant (Zhao et al., 2004). Dimorphic seeds are not only differ in color and morphology, but also differ in dormancy and germination (Li et al., 2005, 2008). Brown seeds are non-dormant and have higher germination percentage than black seeds in salinity, which regulated by the ABA and GA homeostases (Li et al., 2016). Though several studies have been conducted on the salt tolerance of $S$. salsa seeds during germination (Li et al., 2005, 2016), there are few studies concerning salt tolerance of young seedlings grown from dimorphic seeds and $\mathrm{NaCl}$ is generally the only one kind of salt used in the experiment (Duan et al., 2007; Song et al., 2008). The shoot length is more sensitive to high salinity for $S$. salsa seedlings grown from black seeds than that from brown seeds (Song et al., 2008). Duan et al. (2007) tested the effect of different types of salinity on germination inhibition of $S$. salsa and found that the effect order is $\mathrm{MgCl}_{2}>\mathrm{Na}_{2} \mathrm{SO}_{4}>\mathrm{Na}_{2} \mathrm{CO}_{3}>\mathrm{NaCl}>\mathrm{MgSO}_{4}$. Seedling growth is accelerated by the low concentration of salinity $(0.05-0.1 \mathrm{mM})$. However, the seed type of $S$. salsa used in this experiment is not mentioned. Meanwhile, there is no comprehensive analysis on germination responses of dimorphic seeds of $S$. salsa to light condition and different temperature regimes. Furthermore, S. salsa seeds used in germination studies are mainly from the humid regions and not mentioned the seed type (Song et al., 2008; Gao et al., 2018). Thus, germination characteristics of dimorphic seeds of S. salsa to different environmental factors and seedling growth are not well recorded, especially for this species grown in arid saline soils.

Light is an important environmental factor and the responses of seeds to it can control the time and place of seed germination (Pons, 2014). Light can promote or inhibit seed germination via light-mediated signaling network, and might has no significant effect (Yang et al., 2020). Non-dormant seeds are generally not sensitive to light during germination, whereas photoblastism is very common for seeds with nondeep physiological dormancy (Baskin and Baskin, 2014). Effects of light on seed germination depend on plant species and other environmental factors during germination (Qu et al., 2008; Nisar et al., 2019a; Yang and Chen, 2020). Even for seeds from the same species, the germination responses to light can be dramatically different. For example, light does not affect germination of non-dormant brown seeds of Suaeda aralocaspica, but promotes germination of cold-stratified black seeds, especially for black seeds after stratification in darkness (Wang et al., 2017).

Temperature is one of the most important environmental factors for change of seed dormancy and germination velocity (Fenner and Thompson, 2005). The temperature requirement for germination is determined by the plant species, source of the seeds, genetic differences with a given species, the age of the seeds, as well as by the seed position on a single plant (Gutterman, 2002; Bhatt et al., 2020). Generally, the temperature range for germination is wider for nondormant seeds than that for dormant seeds (Baskin and Baskin, 2014). Furthermore, the interaction of light and temperature on germination is demonstrated in some species (Li et al., 2005; Wang et al., 2017). Therefore, studying the effects of light conditions, temperature range, and the interdependence between light and temperature on seed germination is essential to understand seed germination strategy of $S$. salsa in the field.

High soil salinity can inhibit seed germination via osmotic effect and toxic effect (Gul et al., 2013; Song et al., 2017). Although the toxic effects on the hydrated seeds of halophytes have been reported, the decline in germination caused by salinity is primarily osmotic effect (Rasheed et al., 2019). For example, the brown seeds of $S$. aralocaspica can germinate to $10 \%$ at $1400 \mathrm{mM} \mathrm{NaCl}$. Furthermore, they are able to endure prolonged exposure to high concentration of $\mathrm{NaCl}(4000 \mathrm{mM})$ and germinate normally when salt stress is removed (Wang et al., 2008). Compared with adult plants, germinating seeds and young seedlings are more sensitive to salinity (Gul et al., 2013). However, the quantitative comparison of salt tolerance between germinating seeds and young seedlings is scarce. The ionic composition of the soil can also affect seed germination and seedling growth (Zhang et al., 2018). Salinity problems are mainly due to excess $\mathrm{Na}^{+}$with $\mathrm{Cl}^{-}$or $\mathrm{SO}_{4}{ }^{2-}$ as the counter ions in the arid northwestern China (Xi et al., 2006).

The aim of this study was to test the effects of light, temperature, and two types of salinity on germination of dimorphic seeds of $S$. salsa, and the effects of both types of salt on seedling growth. Specifically, we asked the following questions: (1) Do dimorphic seeds have the same light and temperature requirements during germination? (2) Which seed type has higher germination percentage and recovery germination under high salinity? (3) Do germinating seeds and thereafter seedlings have the same salt tolerance? The findings will provide essential information for understanding the role of different environmental factors in regulating germination of dimorphic seeds and seedling growth of halophyte $S$. salsa in arid saline desert.

\section{MATERIALS AND METHODS}

\section{Plant Materials}

Freshly mature fruits of $S$. salsa were randomly collected from the population growing in a salt desert of Karamay, northern Xinjiang, China in November 2019. The companion species are Salicornia europaea, Salsola subcrassa, Phragmites australis, and so on. This site belongs to temperate continental desert climate. The annual average temperature is $8.4^{\circ} \mathrm{C}$. The mean annual precipitation is $109 \mathrm{~mm}$ and mean annual potential evaporation is $3009 \mathrm{~mm}$ (Baiketuerhan et al., 2019).

The fruits were allowed to dry naturally in laboratory room for 2 weeks. Seeds were cleaned and separately sorted according to seed color. Each type of seeds was pooled and stored in plastic bag at room temperature $\left(22 \pm 2^{\circ} \mathrm{C}\right)$ until used in experiments. 


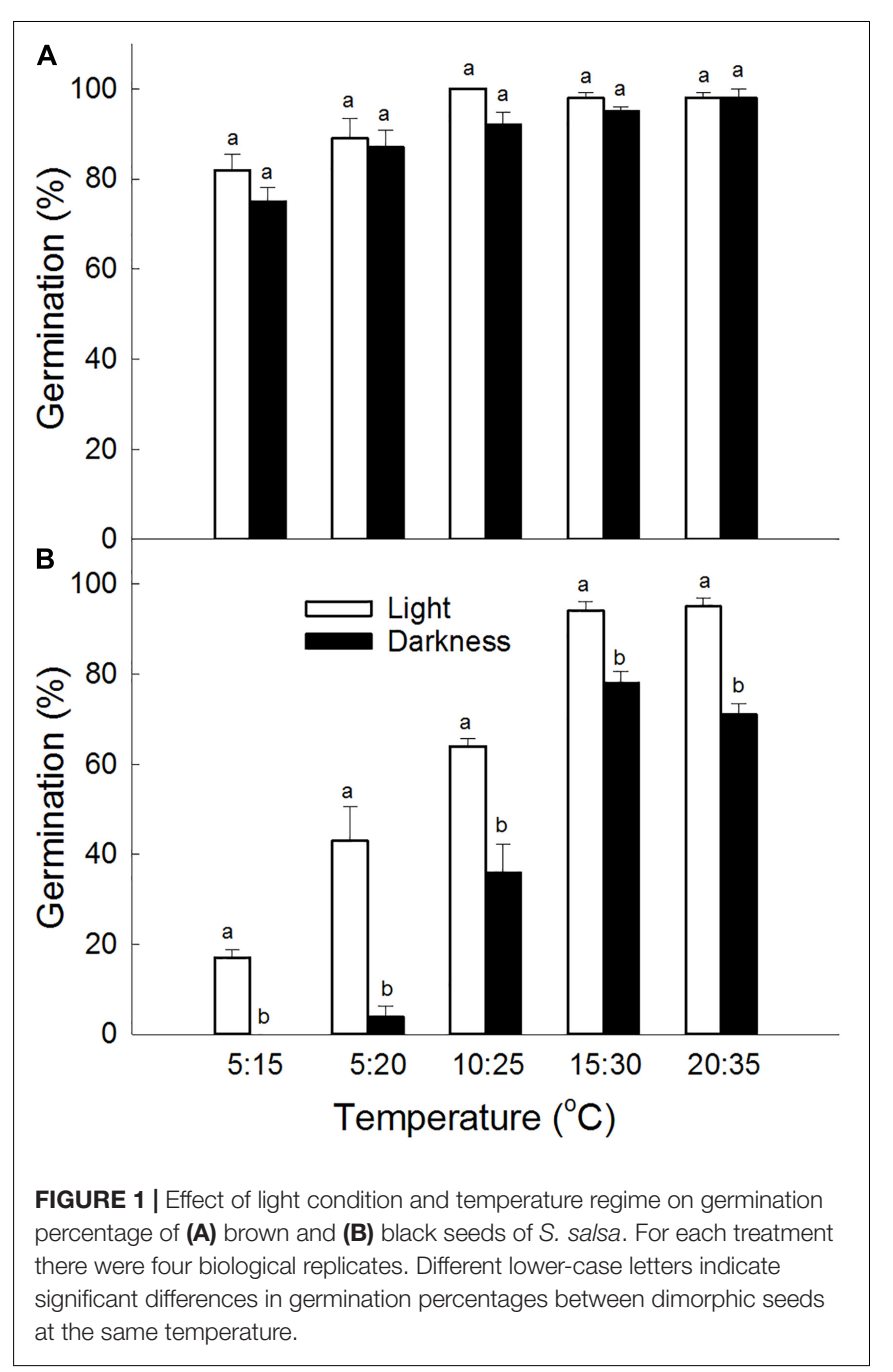

\section{Seed Germination}

\section{Effects of Light and Temperature on Germination}

For each treatment, four biological replicates of 25 seeds were placed in a $50 \mathrm{~mm}$ diameter Petri dish on two layers of No. 1 filter paper moistened with $2.5 \mathrm{ml}$ of deionized water. After covered with lid, the petri dish was sealed with parafilm and then transferred to plant incubator (GXZ380, Jiangnan Instrument Factory, Zhejiang, China). The incubation temperature regimes were 5: $15^{\circ} \mathrm{C}, 5: 20^{\circ} \mathrm{C}, 10$ : $25^{\circ} \mathrm{C}, 15: 30^{\circ} \mathrm{C}$, and $20: 35^{\circ} \mathrm{C}$. The light condition was set to $12 \mathrm{~h} \mathrm{light/darkness} \mathrm{photoperiod} \mathrm{(hereafter} \mathrm{light} \mathrm{treatment)} \mathrm{or}$ constant darkness. For light treatment, higher temperature of each temperature regime was coincided with $12 \mathrm{~h}$ light and lower temperature with 12 darkness. Two layers of aluminum foil were used to wrap the Petri dishes to provide constant darkness. Seeds were incubated for 20 days. Germination test standard for black seeds was $\geq 1 \mathrm{~mm}$ radicle and for brown seeds it was $\geq 2 \mathrm{~mm}$. Seeds under the light treatment were checked every $24 \mathrm{~h}$, and germinated seeds were counted and discarded. Seeds under constant darkness were checked only after 20 days of incubation.
TABLE 1 | Multiple linear regression analysis of germination percentage, germination index, recovery percentage, and final germination percentage of dimorphic seeds, and radicle and shoot length of seedlings grown from dimorphic seeds of S. salsa.

\begin{tabular}{|c|c|c|c|c|}
\hline & & B (SE) & $\beta$ & $P$-value \\
\hline \multirow{3}{*}{$\begin{array}{l}\text { Germination } \\
\text { percentage }\end{array}$} & Seed type & $-20.92(1.855)$ & -0.295 & $<0.001$ \\
\hline & Salt type & $-12.44(1.855)$ & -0.176 & $<0.001$ \\
\hline & Salt concentration & $-0.077(0.002)$ & -0.865 & $<0.001$ \\
\hline \multirow{3}{*}{$\begin{array}{l}\text { Germination } \\
\text { index }\end{array}$} & Seed type & $-37.198(1.933)$ & -0.536 & $<0.001$ \\
\hline & Salt type & $-9.442(1.933)$ & -0.136 & $<0.001$ \\
\hline & Salt concentration & $-0.064(0.002)$ & -0.737 & $<0.001$ \\
\hline \multirow{3}{*}{$\begin{array}{l}\text { Recovery } \\
\text { percentage }\end{array}$} & Seed type & 0.038 (0.003) & 0.603 & $<0.001$ \\
\hline & Salt type & $1.958(2.028)$ & 0.039 & 0.336 \\
\hline & Salt concentration & 27.961 (2.028) & 0.559 & $<0.001$ \\
\hline \multirow{3}{*}{$\begin{array}{l}\text { Final } \\
\text { germination } \\
\text { percentage }\end{array}$} & Seed type & $1.280(2.839)$ & 0.025 & 0.653 \\
\hline & Salt type & $-8.960(2.839)$ & -0.176 & 0.002 \\
\hline & Salt concentration & $-0.039(0.004)$ & -0.601 & $<0.001$ \\
\hline \multirow[t]{3}{*}{ Shoot length } & Seed type & $-2.526(0.173)$ & -0.343 & $<0.001$ \\
\hline & Salt type & $-1.174(0.173)$ & -0.159 & $<0.001$ \\
\hline & Salt concentration & $-0.007(0)$ & -0.799 & $<0.001$ \\
\hline \multirow[t]{3}{*}{ Radicle length } & Seed type & $-2.472(0.282)$ & -0.255 & $<0.001$ \\
\hline & Salt type & $-0.324(0.282)$ & -0.033 & 0.252 \\
\hline & Salt concentration & $-0.009(0)$ & -0.774 & $<0.001$ \\
\hline
\end{tabular}

\section{Effects of Salinity on Germination and Recovery}

Analytical reagent grade of $\mathrm{NaCl}$ and $\mathrm{Na}_{2} \mathrm{SO}_{4}$ (Fuchen Chemical Reagent Co., Ltd., Tianjin, China) were used to study the effects of salinity on germination and recovery of dimorphic seeds of $S$. salsa. For each treatment, five biological replicates of 25 seeds were incubated in Petri dishes on two layers of filter paper moistened with $2.5 \mathrm{ml}$ solution $(0,50,100,200,300$, $400,600,800,1000,1200 \mathrm{mM}$ of $\mathrm{NaCl}$ and $\mathrm{Na}_{2} \mathrm{SO}_{4}$ ). Then the Petri dishes were placed under $10: 25^{\circ} \mathrm{C}$ and light treatment for 20 days. Based on the first experiment, $10: 25^{\circ} \mathrm{C}$ is suitable for germination. Furthermore, it represents the temperature of May and September in this area. The Petri dishes were checked daily.

Ungerminated seeds in each Petri dish were rinsed three times with deionized water and then incubated for 5 days in a new Petri dish that filled with $2.5 \mathrm{ml}$ deionized water under the above mentioned temperature and light conditions. Recovery germination was checked every day.

Germination percentage $(\%)=$ (the number of seeds that germinated in each solution/total number of seeds tested in in each solution $) \times 100$. Recovery percentage $(\%)=($ the number of seeds germinated in recovery experiment in each solution/the number of ungerminated seeds in each solution) $\times 100$. Final germination percentage $(\%)=$ (total number of seeds that germinated in each solution plus those that recovered to germinate in deionized water/the total number of seeds tested in each solution) $\times 100$. The velocity of germination was estimated using a modified Timson's index of germination velocity (Khan et al., 2001). 


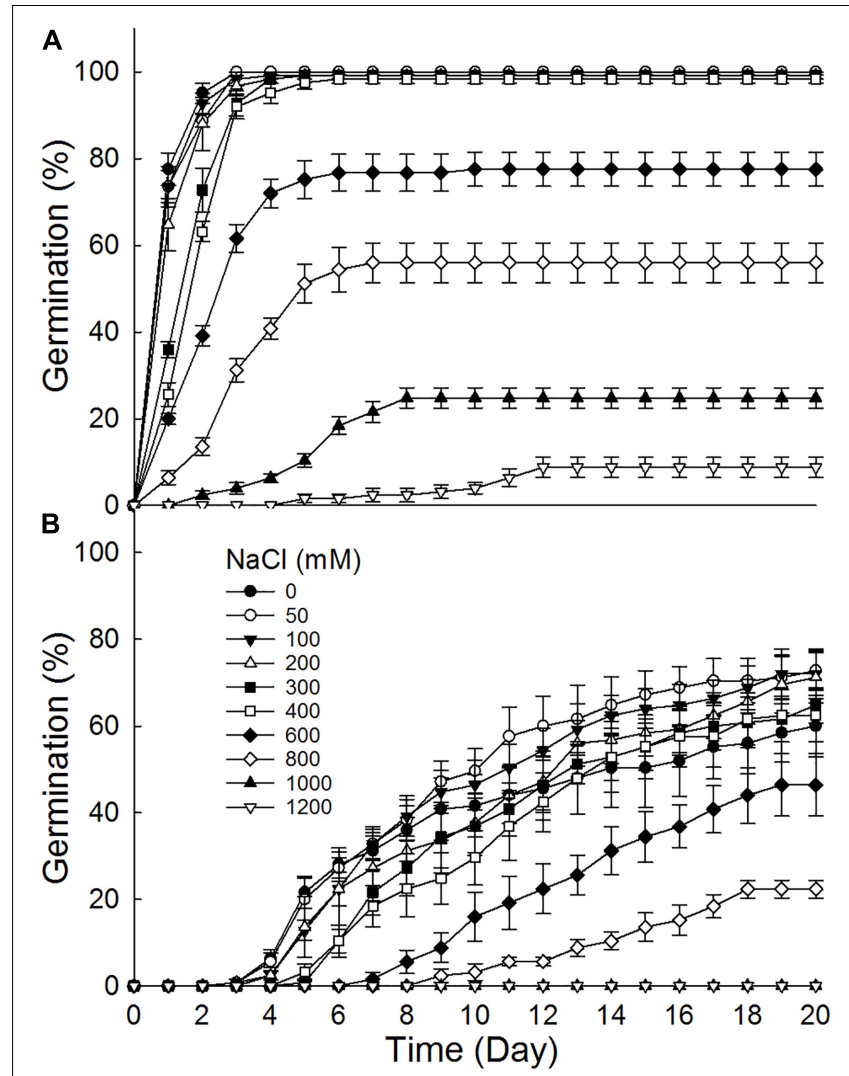

FIGURE 2 | Effect of $\mathrm{NaCl}$ on germination of (A) brown and (B) black seeds of S. salsa incubated at $10: 25^{\circ} \mathrm{C}$ in the $12 \mathrm{~h}$ daylight photoperiod for 20 days. For each treatment there were five biological replicates.

\section{Seedling Growth}

During the germination process under different salinity, seven germinated seeds in each Petri dish were selected according to the germination time. Then, they were incubated in a new Petri dish with the same salt treatment under $10: 25^{\circ} \mathrm{C}$ and light treatment for 20 days. Radicle length and shoot length were measured for the two longest seedlings in each Petri dish by the microscope with Olumpus cellSens software. Thus, there were 10 replicates for each treatment. Radicle tolerance index $(\%)=$ (length of the radicle in different salt treatments/length of the radicle under deionized water treatment $) \times 100$. Shoot tolerance index $(\%)=$ (length of the shoot in different salt treatments/length of the shoot under deionized water treatment $) \times 100$.

\section{Data Analysis}

All data were expressed as mean \pm SE. The data did not meet the assumptions for three-way ANOVA. In light and temperature experiment, data for germination percentage were analyzed by linear regression using the linear regression method (all independent variables were entered into the equation in a single step). The multiple linear regression model included seed type (brown and black seeds), light condition ( $12 \mathrm{~h} \mathrm{light/darkness}$ photoperiod and constant darkness), and temperature regimes (5: $15^{\circ} \mathrm{C}, 5: 20^{\circ} \mathrm{C}, 10: 25^{\circ} \mathrm{C}, 15: 30^{\circ} \mathrm{C}$, and $20: 35^{\circ} \mathrm{C}$ ).

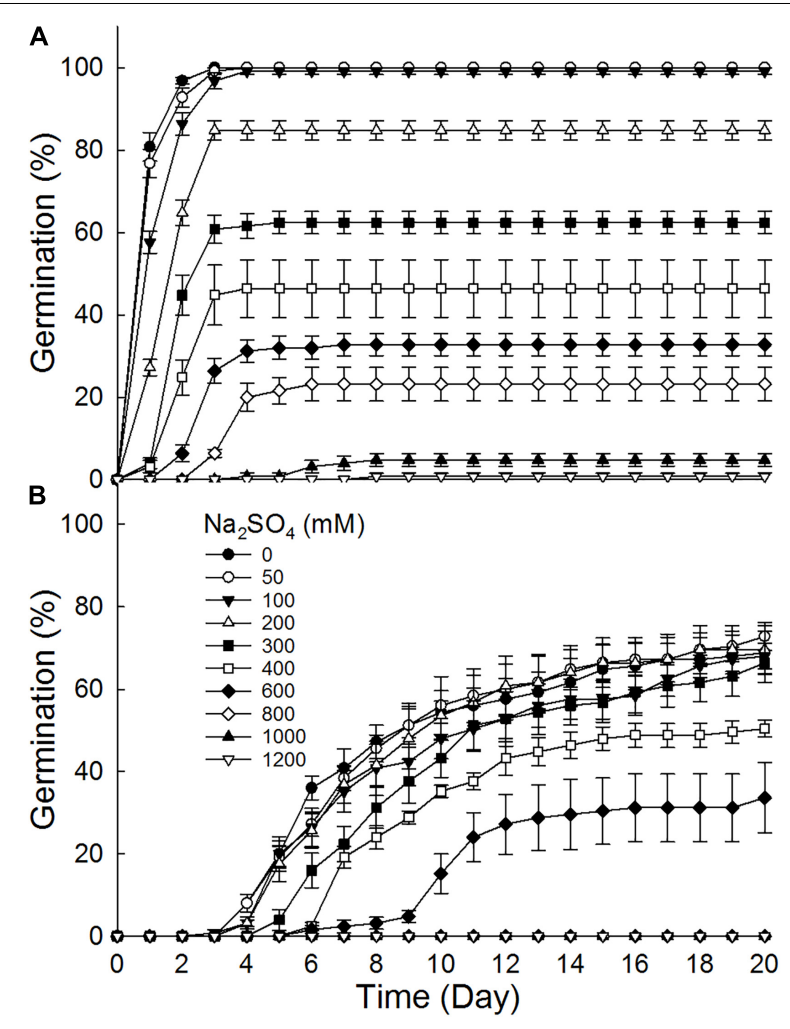

FIGURE 3 | Effect of $\mathrm{Na}_{2} \mathrm{SO}_{4}$ on germination of (A) brown and (B) black seeds of $\mathrm{S}$. salsa incubated at $10: 25^{\circ} \mathrm{C}$ in the $12 \mathrm{~h}$ daylight photoperiod for 20 days. For each treatment there were five biological replicates.

TABLE 2 | Germination index of dimorphic seeds of $S$. salsa under different $\mathrm{NaCl}$ and $\mathrm{Na}_{2} \mathrm{SO}_{4}$ concentration.

\begin{tabular}{|c|c|c|c|c|}
\hline \multirow{2}{*}{$\begin{array}{l}\text { Concentration } \\
(\mathrm{mM})\end{array}$} & \multicolumn{2}{|c|}{$\mathrm{NaCl}$} & \multicolumn{2}{|c|}{$\mathrm{Na}_{2} \mathrm{SO}_{4}$} \\
\hline & Brown seed & Black seed & Brown seed & Black seed \\
\hline 0 & $98.6 \pm 0.3 A a$ & $36.3 \pm 5.3 B a$ & $98.9 \pm 0.2 A a$ & $44.7 \pm 3.4 \mathrm{Ba}$ \\
\hline 50 & $98.1 \pm 0.2 A a$ & $44.3 \pm 4.0 B a$ & $98.4 \pm 0.2 A a$ & $45.2 \pm 3.3 B a$ \\
\hline 100 & $97.6 \pm 0.9 A a$ & $41.8 \pm 3.5 B a$ & $96.4 \pm 0.8 A a$ & $40.6 \pm 3.4 B a b$ \\
\hline 200 & $96.8 \pm 0.7 \mathrm{Aa}$ & $38.0 \pm 4.9 B a$ & $80.9 \pm 2.3 A b$ & $43.9 \pm 4.4 \mathrm{Ba}$ \\
\hline 300 & $94.4 \pm 0.8 A a$ & $34.2 \pm 3.6 B a$ & $58.5 \pm 2.7 A c$ & $36.8 \pm 3.3 B a b$ \\
\hline 400 & $92.5 \pm 1.1 \mathrm{Aa}$ & $32.3 \pm 4.7 \mathrm{Bab}$ & $43.1 \pm 6.5 A d$ & $28.8 \pm 1.7 A b$ \\
\hline 600 & $71.4 \pm 3.5 A b$ & $19.0 \pm 3.4 B b c$ & $29.4 \pm 2.5 A e$ & $16.3 \pm 4.2 B C$ \\
\hline 800 & $49.1 \pm 3.7 A c$ & $7.5 \pm 1.1 B c d$ & $20.3 \pm 3.6 \mathrm{Ae}$ & $0.0 \pm 0.0 B d$ \\
\hline 1000 & $19.3 \pm 1.7 A d$ & $0.0 \pm 0.0 B d$ & $4.5 \pm 1.2 A f$ & $0.0 \pm 0.0 B d$ \\
\hline 1200 & $5.0 \pm 1.4 A e$ & $0.0 \pm 0.0 B d$ & $0.5 \pm 0.5 A f$ & $0.0 \pm 0.0 A d$ \\
\hline
\end{tabular}

For each treatment there were five biological replicates. Different lower-case letters indicate significant differences ( $P<0.05$, Tukey's test) in germination indexes among different concentration for the same seed type and salt type. Different upper-case letters indicate significant differences $(P<0.05$, Tukey's test) between dimorphic seeds at the same concentration of $\mathrm{NaCl}$ or $\mathrm{Na}_{2} \mathrm{SO}_{4}$.

These thermoperiods represent the mean daily maximum and minimum monthly temperatures at the research field during the growing season: 5:15 (early April and October), 5:25 (late April), 10:25 (May and September), 15:30 (June and August), 
TABLE 3 | Recovery percentage of dimorphic seeds of S. salsa in deionized water after $\mathrm{NaCl}$ or $\mathrm{Na}_{2} \mathrm{SO}_{4}$ pretreatment.

\begin{tabular}{|c|c|c|c|c|}
\hline \multirow[t]{2}{*}{ Concentration (mM) } & \multicolumn{2}{|c|}{$\mathrm{NaCl}$} & \multicolumn{2}{|c|}{$\mathrm{Na}_{2} \mathrm{SO}_{4}$} \\
\hline & Brown seed & Black seed & Brown seed & Black seed \\
\hline 0 & $0.0 \pm 0.0 A c$ & $2.0 \pm 2.0 A f$ & $0.0 \pm 0.0 A c$ & $4.5 \pm 2.9 A C$ \\
\hline 50 & $0.0 \pm 0.0 A c$ & $2.0 \pm 2.0 A f$ & $0.0 \pm 0.0 A c$ & $2.9 \pm 2.9 A C$ \\
\hline 100 & $0.0 \pm 0.0 A c$ & $0.0 \pm 0.0 A f$ & $0.0 \pm 0.0 A c$ & $4.3 \pm 2.7 A c$ \\
\hline 200 & $0.0 \pm 0.0 A c$ & $16.2 \pm 5.9 A e f$ & $0.0 \pm 0.0 A c$ & $7.8 \pm 4.8 A C$ \\
\hline 300 & $0.0 \pm 0.0 A c$ & $20.1 \pm 8.7$ Adef & $0.0 \pm 0.0 B c$ & $19.3 \pm 5.5 A c$ \\
\hline 400 & $0.0 \pm 0.0 B c$ & $27.2 \pm 7.7$ Acde & $0.0 \pm 0.0 B c$ & $18.8 \pm 4.2 A c$ \\
\hline 600 & $0.0 \pm 0.0 B c$ & $42.9 \pm 6.8 A b c$ & $0.0 \pm 0.0 B c$ & $42.7 \pm 6.9 A b$ \\
\hline 800 & $3.3 \pm 3.3 B b c$ & $41.1 \pm 3.0 \mathrm{Abcd}$ & $1.2 \pm 1.2 B C$ & $62.4 \pm 3.7 \mathrm{Aa}$ \\
\hline 1000 & $7.3 \pm 1.1 B a b$ & $54.4 \pm 4.8 A b$ & $6.8 \pm 1.0 B b$ & $76.0 \pm 4.7 \mathrm{Aa}$ \\
\hline 1200 & $9.6 \pm 1.6 \mathrm{Ba}$ & $79.2 \pm 3.2 \mathrm{Ba}$ & $17.0 \pm 2.8 B a$ & $80.8 \pm 6.4 \mathrm{Aa}$ \\
\hline
\end{tabular}

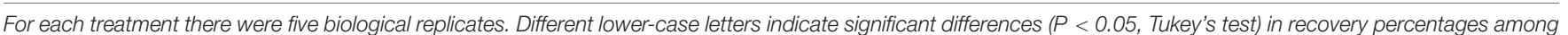

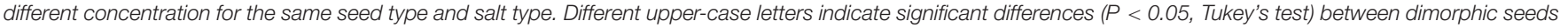
at the same concentration of $\mathrm{NaCl}$ or $\mathrm{Na}_{2} \mathrm{SO}_{4}$.

TABLE 4 | Final germination percentage of dimorphic seeds of $\mathrm{S}$. salsa after treated with different concentration of $\mathrm{NaCl}_{\text {or }} \mathrm{Na}_{2} \mathrm{SO}_{4}$.

\begin{tabular}{|c|c|c|c|c|}
\hline \multirow[t]{2}{*}{ Concentration (mM) } & \multicolumn{2}{|c|}{$\mathrm{NaCl}$} & \multicolumn{2}{|c|}{$\mathrm{Na}_{2} \mathrm{SO}_{4}$} \\
\hline & Brown seed & Black seed & Brown seed & Black seed \\
\hline 0 & $100.0 \pm 0.0 A a$ & $60.8 \pm 7.2 B a b$ & $100.0 \pm 0.0 A a$ & $70.4 \pm 4.8 B a b$ \\
\hline 50 & $100.0 \pm 0.0 \mathrm{Aa}$ & $73.6 \pm 4.1 B a b$ & $100.0 \pm 0.0 A a$ & $73.6 \pm 3.5 B a b$ \\
\hline 100 & $99.2 \pm 0.8 A a$ & $72.0 \pm 5.8 B a b$ & $99.2 \pm 0.8 A a$ & $69.6 \pm 2.4 B a b$ \\
\hline 200 & $99.2 \pm 0.8 \mathrm{Aa}$ & $76.0 \pm 5.5 B a b$ & $84.8 \pm 2.3 A b$ & $72.8 \pm 4.5 B a b$ \\
\hline 300 & $99.2 \pm 0.8 A a$ & $72.0 \pm 4.6 B a b$ & $62.4 \pm 2.7 B C$ & $73.6 \pm 3.5 A a b$ \\
\hline 400 & $98.4 \pm 1.0 \mathrm{Aa}$ & $72.8 \pm 4.1 B a b$ & $46.4 \pm 7.0 A c$ & $60.0 \pm 1.3 A b$ \\
\hline 600 & $77.6 \pm 3.9 A b$ & $68.0 \pm 7.2 A a b$ & $32.8 \pm 2.7 B d$ & $63.2 \pm 4.5 A a b$ \\
\hline 800 & $57.6 \pm 4.5 A c$ & $54.4 \pm 2.0 A b$ & $24.8 \pm 4.8 B d e$ & $62.4 \pm 3.7 A a b$ \\
\hline 1000 & $30.4 \pm 1.6 B d$ & $54.4 \pm 4.8 A b$ & $12.8 \pm 1.5 B e$ & $76.0 \pm 4.7 A a b$ \\
\hline 1200 & $17.6 \pm 2.0 B e$ & $79.2 \pm 3.2 A a$ & $17.6 \pm 3.2 B e$ & $80.8 \pm 6.4 A a$ \\
\hline
\end{tabular}

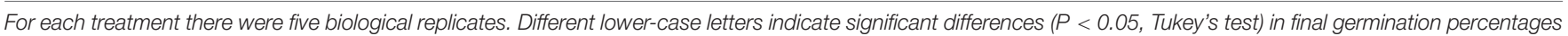

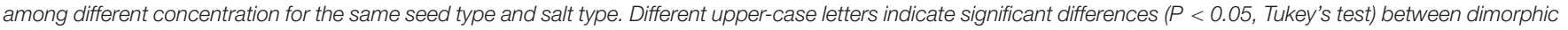
seeds at the same concentration of $\mathrm{NaCl}$ or $\mathrm{Na}_{2} \mathrm{SO}_{4}$.

and $20: 35^{\circ} \mathrm{C}$ (July). In salinity experiment, data for germination and seedling growth were also analyzed by linear regression. The multiple linear regression model included seed type (brown and black seeds), salt type ( $\mathrm{NaCl}$ and $\left.\mathrm{Na}_{2} \mathrm{SO}_{4}\right)$, and salt concentration $(50,100,200,300,400,600,800,1000$, and $1200 \mathrm{mM})$. Oneway ANOVA and Tukey's test were used to determine significant differences among different temperatures or salinity treatments for each seed type of $S$. salsa. Independent samples $t$-test was used to determine whether there was difference between brown and black seeds under the same conditions.

\section{RESULTS}

\section{Seed Germination}

\section{Effects of Light and Temperature on Germination}

Germination percentage was significantly affected by seed type $(P<0.001)$, light condition $(P<0.001)$, and temperature $(P<0.001)$. Germination percentages of brown seeds of
S. salsa were higher than that of black seeds under the same conditions (Figure 1). There was no significant difference in germination percentage between incubation in light and incubation in darkness for brown seeds. However, for black seeds, germination percentage in light was significantly higher than that in darkness under the same temperature. Although temperature significantly $(P<0.001)$ affected germination of brown seeds, germination percentages in different temperature combinations at 5: $20^{\circ} \mathrm{C}, 10: 25^{\circ} \mathrm{C}, 15: 30^{\circ} \mathrm{C}$, and $20: 35^{\circ} \mathrm{C}$ did not show significantly differences. For black seeds, germination percentages increased as the temperature increased from $5: 15^{\circ} \mathrm{C}$ to $15: 30^{\circ} \mathrm{C}$ (Figure 1).

\section{Effects of Salinity on Germination and Recovery}

Germination percentage and germination index were significantly affected by seed type $(P<0.001)$, salt type $(P<0.001)$ and salt concentration $(P<0.001)$ (Table 1$)$. Recovery percentage was significantly affected by seed type $(P<0.001)$ and salt concentration $(P<0.001)$. Final germination 


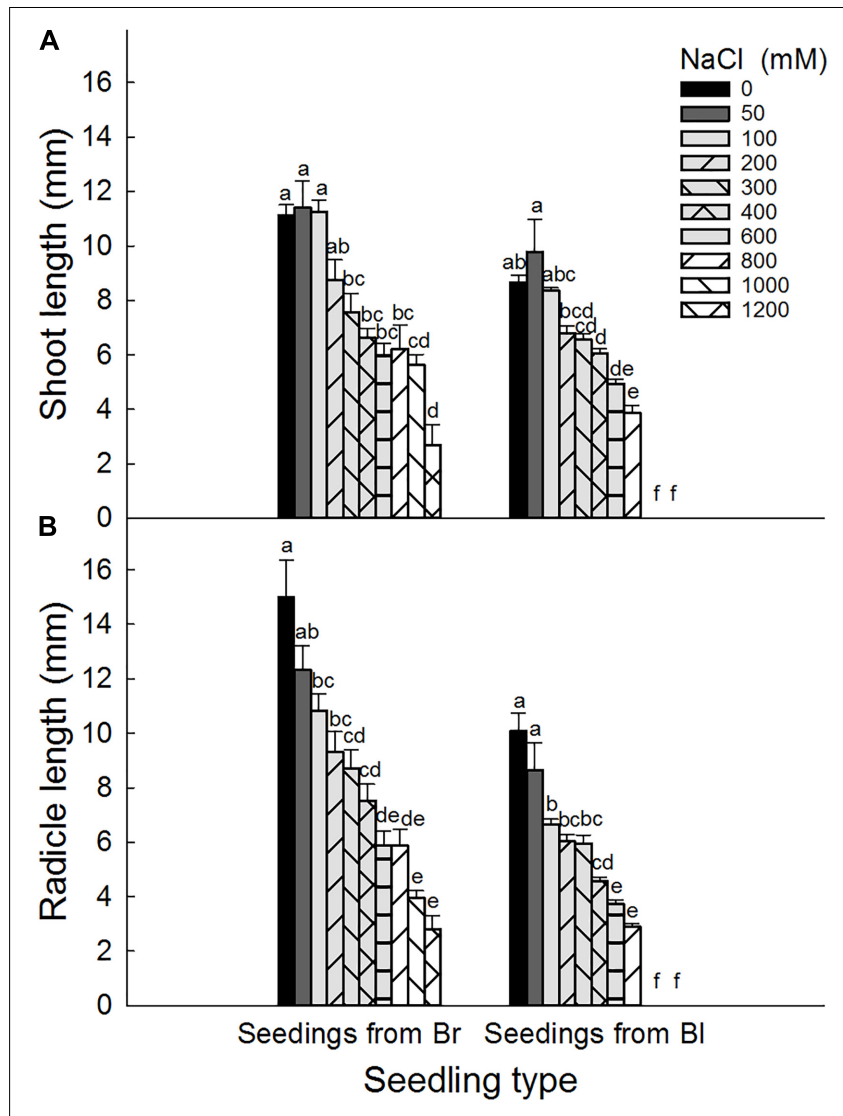

FIGURE 4 | Effect of $\mathrm{NaCl}$ on (A) shoot and (B) radicle length of seedlings grown from dimorphic seeds of $\mathrm{S}$. salsa. Br, brown seeds; BI, black seeds. For each treatment there were 10 biological replicates. Different lower-case letters indicate significant differences in shoot or radicle lengths of seedlings grown from each seed type. percentage was significantly affected by salt type $(P=0.002)$ and salt concentration $(P<0.001)$ (Table 1).

Brown seeds germinated to $8.8-100 \%$ at $0-1200 \mathrm{mM} \mathrm{NaCl}$, while black seeds germinated to $0-72 \%$ at $0-1000 \mathrm{mM}$ (Figure 2). Furthermore, brown seeds germinated to higher percentages than black seeds at the same $\mathrm{NaCl}$ concentration. Germination percentage of brown seeds at $800 \mathrm{mM} \mathrm{NaCl}$ was $56 \%$, whereas that of black seeds was only $22.4 \%$. The increase of $\mathrm{NaCl}$ concentration gradually decreased germination percentages of dimorphic seeds. Dimorphic seeds in $\mathrm{Na}_{2} \mathrm{SO}_{4}$ solutions showed a different pattern in germination (Figure 3). Brown seeds had higher germination percentage than black seeds at low and high $\mathrm{Na}_{2} \mathrm{SO}_{4}$ concentrations. However, dimorphic seeds had similar germination percentage at middle concentration (300$600 \mathrm{mM}$ ) of $\mathrm{Na}_{2} \mathrm{SO}_{4}$. The increase of $\mathrm{Na}_{2} \mathrm{SO}_{4}$ concentration also decreased germination of both types of seeds. At the same salt concentration, brown seeds generally had higher germination percentage in $\mathrm{NaCl}$ solution than that in $\mathrm{Na}_{2} \mathrm{SO}_{4}$ solution. At the relatively high concentration (400-800 mM), black seeds had higher germination percentage in $\mathrm{NaCl}$ than that in $\mathrm{Na}_{2} \mathrm{SO}_{4}$ solution (Figures 2, 3).

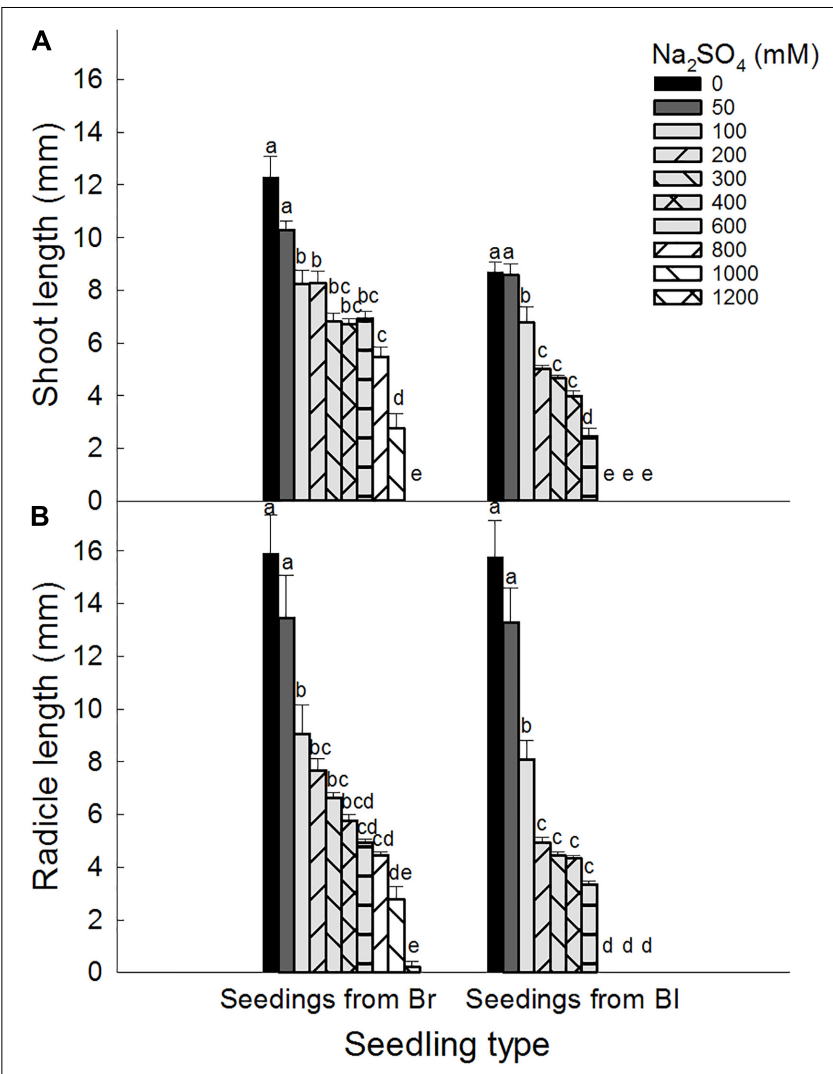

FIGURE 5 | Effect of $\mathrm{Na}_{2} \mathrm{SO}_{4}$ on (A) shoot and (B) radicle length of seedlings grown from dimorphic seeds of $\mathrm{S}$. salsa. Br, brown seeds; BI, black seeds. For each treatment there were 10 biological replicates. Different lower-case letters indicate significant differences in shoot or radicle lengths of seedlings grown from each seed type.

Germination indexes for dimorphic seeds under different salinity had the similar trend as germination percentage (Table 2). But the difference of germination index between dimorphic seeds was more significant than that of germination percentage. Germination index of brown seeds was higher than that of black seeds at the same salt concentration. The highest gemination index for brown seeds in $\mathrm{NaCl}$ solutions was 98.6, whereas that for black seeds was 44.3 . The highest gemination index for brown seeds in $\mathrm{Na}_{2} \mathrm{SO}_{4}$ solutions was 98.9 , but that for black was 45.2.

Germination recovery percentage of brown seeds was lower than that of black seeds after the pretreatment with the same salt concentration (Table 3 ). Recovery percentages of brown seeds were 0 after pretreatment with $0-600 \mathrm{mM} \mathrm{NaCl}$ or $\mathrm{Na}_{2} \mathrm{SO}_{4}$. After pretreatment with high $\mathrm{NaCl}$ concentration (800$1200 \mathrm{mM}$ ), recovery percentages of brown seeds were 3.3-9.6\%, however after pretreatment with high $\mathrm{Na}_{2} \mathrm{SO}_{4}$ concentration, recovery percentages of brown seeds were $1.2-17.0 \%$. As the pretreatment salinity increased, the recovery percentages of black seeds showed a clear increasing trend. As the concentration of pretreated $\mathrm{NaCl}$ increased from 0 to $1200 \mathrm{mM}$, the recovery percentage of black seeds increased from 0 to $79.2 \%$. Similarly, 

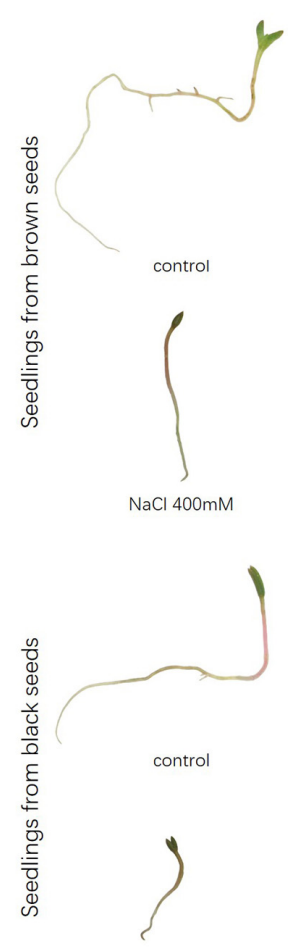

$\mathrm{NaCl} 400 \mathrm{mM}$
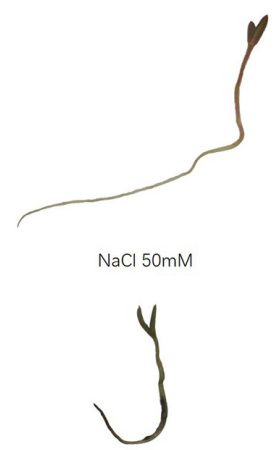

$\mathrm{NaCl} 600 \mathrm{mM}$
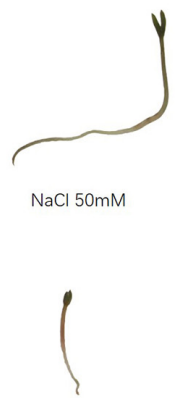

$\mathrm{NaCl} 600 \mathrm{mM}$

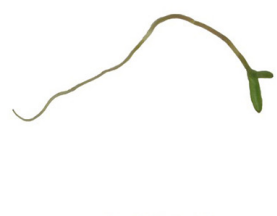

$\mathrm{NaCl} 100 \mathrm{mM}$

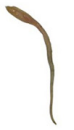

$\mathrm{NaCl} 800 \mathrm{mM}$

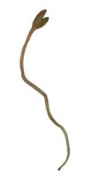

$\mathrm{NaCl} 100 \mathrm{mM}$

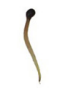

$\mathrm{NaCl} 800 \mathrm{mM}$

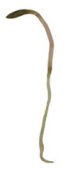

$\mathrm{NaCl} 200 \mathrm{mM}$

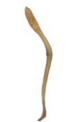

$\mathrm{NaCl} 1000 \mathrm{mM}$

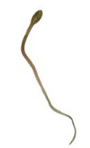

$\mathrm{NaCl} 200 \mathrm{mM}$

$\mathrm{NaCl} 1000 \mathrm{mM}$

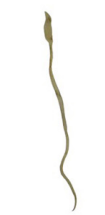

$\mathrm{NaCl} 300 \mathrm{mM}$

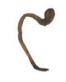

$\mathrm{NaCl} 1200 \mathrm{mM}$

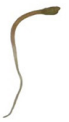

$\mathrm{NaCl} 300 \mathrm{mM}$

$\bullet$

$\mathrm{NaCl} 1200 \mathrm{mM}$

FIGURE 6 | Radicle elongation of seedlings grown from dimorphic seeds of S. salsa after 20 days of incubation under different concentrations of $\mathrm{NaCl}$.

as the pretreatment $\mathrm{Na}_{2} \mathrm{SO}_{4}$ increased from 0 to $1200 \mathrm{mM}$, the recovery percentage of black seeds increased from 4.5 to $80.8 \%$ (Table 3).

The final germination percentages of brown seeds were significantly higher than that of black seeds at $0-400 \mathrm{mM}$ $\mathrm{NaCl}$ (Table 4). However, the final germination percentages of brown seeds were significantly lower than that of black seeds at $1000-1200 \mathrm{mM} \mathrm{NaCl}$. As $\mathrm{NaCl}$ concentration increased from 0 to $1200 \mathrm{mM}$, final germination percentages of brown seeds decreased from 100 to $17.6 \%$. But the final germination percentages of black seeds maintained a high level. For $\mathrm{Na}_{2} \mathrm{SO}_{4}$ treatments, brown seeds had higher final germination percentages than black seeds at low salinity (0-200 mM). But at high salinity (300-1200 mM), brown seeds had lower final germination percentages than black seeds. Final germination percentages of brown seeds also showed a clear decreasing trend under $\mathrm{Na}_{2} \mathrm{SO}_{4}$ treatments. When the concentration of salinity was $200-1000 \mathrm{mM}$, the brown seeds with $\mathrm{NaCl}$ treatment had higher final germination percentages than brown seeds with the same $\mathrm{Na}_{2} \mathrm{SO}_{4}$ concentration.

\section{Seedling Growth}

Shoot lengths were significantly affected by seed type $(P<0.001)$, salt type $(P<0.001)$, and salt concentration $(P<0.001)$. However, radicle lengths were significantly affected by seed type $(P<0.001)$ and salt concentration $(P<0.001)$ (Table 1$)$.
Brown seeds were generally had higher length of shoot and radicle than black seeds at the same $\mathrm{NaCl}$ or $\mathrm{Na}_{2} \mathrm{SO}_{4}$ concentration (Figures 4, 5). At the same concentration, seedlings grown from the same type of seeds generally had higher length and better growth in $\mathrm{NaCl}$ solution than that in $\mathrm{Na}_{2} \mathrm{SO}_{4}$ solution. Radicle length of brown seeds was $2.8 \pm 0.5 \mathrm{~mm}$ at $1200 \mathrm{mM} \mathrm{NaCl}$ solution, whereas only $0.2 \pm 0.2 \mathrm{~mm}$ at the same concentration of $\mathrm{Na}_{2} \mathrm{SO}_{4}$. Shoot and radicle length of seedlings grown from dimorphic seeds generally deceased with the increase of salinity. Radicle growth of black seeds was almost completely inhibited by $1000 \mathrm{mM} \mathrm{NaCl}$, and by $800 \mathrm{mM} \mathrm{Na}_{2} \mathrm{SO}_{4}$ (Figures 6, 7).

Shoot and radicle tolerance index showed similar trends in different salt solutions as the changes of radicle and shoot length (Tables 5, 6). Both indexes were generally higher in $\mathrm{NaCl}$ solution than that in the same $\mathrm{Na}_{2} \mathrm{SO}_{4}$ concentration. Radicle tolerance index was more sensitive to salt toxicity than shoot tolerance index. For example, the radicle tolerance index was 57.8 for seedlings grown from black seeds in $200 \mathrm{mM}$ $\mathrm{Na}_{2} \mathrm{SO}_{4}$ solutions. However, the shoot tolerance index was 31.3 (Tables 5, 6).

\section{DISCUSSION}

Although the effects of abiotic factors on seed germination of S. salsa have been previously reported (Song et al., 2008; 


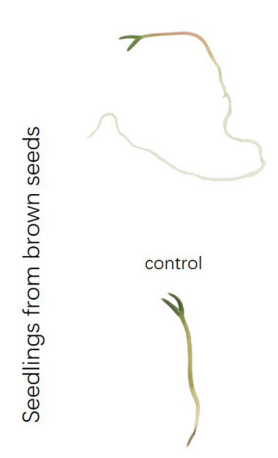

$\mathrm{Na}_{2} \mathrm{SO}_{4} 400 \mathrm{mM}$

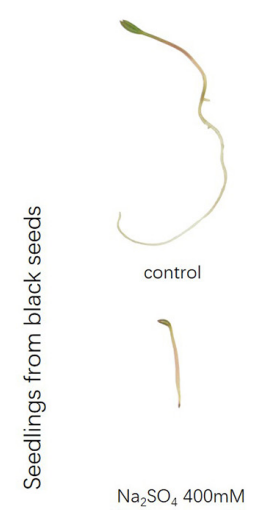

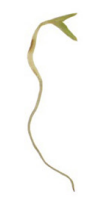

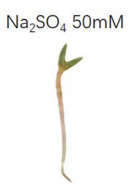

$\mathrm{Na}_{2} \mathrm{SO}_{4} 600 \mathrm{mM}$

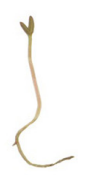

$\mathrm{Na}_{2} \mathrm{SO}_{4} 50 \mathrm{mM}$

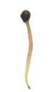

$\mathrm{Na}_{2} \mathrm{SO}_{4} 600 \mathrm{mM}$
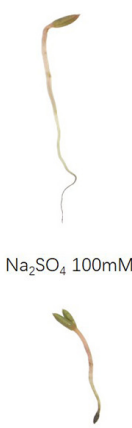

$\mathrm{Na}_{2} \mathrm{SO}_{4} 800 \mathrm{mM}$

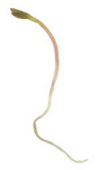

$\mathrm{Na}_{2} \mathrm{SO}_{4} 100 \mathrm{mM}$

$\mathrm{Na}_{2} \mathrm{SO}_{4} 800 \mathrm{mM}$
)

$\mathrm{Na}_{2} \mathrm{SO}_{4} 200 \mathrm{mM}$

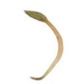

$\mathrm{Na}_{2} \mathrm{SO}_{4} 1000 \mathrm{mM}$

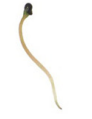

$\mathrm{Na}_{2} \mathrm{SO}_{4} 200 \mathrm{mM}$

$\mathrm{Na}_{2} \mathrm{SO}_{4} 1000 \mathrm{mM}$

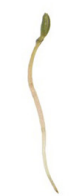

$\mathrm{Na}_{2} \mathrm{SO}_{4} 300 \mathrm{mM}$

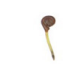

$\mathrm{Na}_{2} \mathrm{SO}_{4} 1200 \mathrm{mM}$

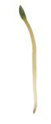

$\mathrm{Na}_{2} \mathrm{SO}_{4} 300 \mathrm{mM}$

$\mathrm{Na}_{2} \mathrm{SO}_{4} 1200 \mathrm{mM}$

FIGURE 7 | Radicle elongation of seedlings grown from dimorphic seeds of $\mathrm{S}$. salsa after 20 days of incubation under different concentrations of $\mathrm{Na}_{2} \mathrm{SO}_{4}$.

TABLE 5 | Shoot tolerance index of $\mathrm{S}$. salsa seedlings grown from dimorphic seeds treated with different concentration of $\mathrm{NaCl}_{2}$ or $\mathrm{Na}_{2} \mathrm{SO}_{4}$.

\begin{tabular}{|c|c|c|c|c|}
\hline \multirow[t]{2}{*}{ Concentration (mM) } & \multicolumn{2}{|c|}{$\mathrm{NaCl}$} & \multicolumn{2}{|c|}{$\mathrm{Na}_{2} \mathrm{SO}_{4}$} \\
\hline & Seedlings from brown seeds & Seedlings from black seeds & Seedlings from brown seeds & Seedlings from black seeds \\
\hline 0 & $100.0 \pm 3.4 \mathrm{Aa}$ & $100.0 \pm 2.5 \mathrm{Aab}$ & $100.0 \pm 6.5 \mathrm{Aa}$ & $100.0 \pm 4.0 \mathrm{Aa}$ \\
\hline 50 & $102.3 \pm 9.0 A a$ & $122.6 \pm 15.0 A a$ & $83.8 \pm 2.9 B a$ & $98.5 \pm 4.8 A a$ \\
\hline 100 & $101.1 \pm 3.8 \mathrm{Aa}$ & $104.5 \pm 1.5 A a b$ & $67.0 \pm 4.4 A b$ & $77.8 \pm 6.8 A b$ \\
\hline 200 & $78.4 \pm 6.8 A a b$ & $84.9 \pm 3.3 A b c$ & $67.4 \pm 3.7 A b$ & $57.8 \pm 1.5 B C$ \\
\hline 300 & $67.8 \pm 6.4 A b c$ & $82.0 \pm 2.9 A b c$ & $55.5 \pm 2.6 A b c$ & $53.7 \pm 1.1 A c$ \\
\hline 400 & $59.4 \pm 3.3 B b c$ & $75.6 \pm 2.4 A C$ & $54.8 \pm 1.6 A b c$ & $45.9 \pm 2.1 B C$ \\
\hline 600 & $53.8 \pm 3.8 A b c$ & $61.7 \pm 2.1$ Acd & $56.3 \pm 2.2 A b c$ & $28.2 \pm 3.6 B d$ \\
\hline 800 & $55.9 \pm 7.8 A b c$ & $48.4 \pm 3.5 A d$ & $44.7 \pm 2.9 A C$ & $0.0 \pm 0.0 B e$ \\
\hline 1000 & $50.5 \pm 3.4 A c d$ & $0.0 \pm 0.0 B e$ & $22.6 \pm 4.5 A d$ & $0.0 \pm 0.0 B e$ \\
\hline 1200 & $24.2 \pm 6.8 A d$ & $0.0 \pm 0.0 B e$ & $0.0 \pm 0.0$ Aef & $0.0 \pm 0.0 A e$ \\
\hline
\end{tabular}

For each treatment there were 10 biological replicates. Different lower-case letters indicate significant differences $(P<0.05$, Tukey's test) in shoot tolerance indexes among different concentration for the same seed type and salt type. Different upper-case letters indicate significant differences ( $P<0.05$, Tukey's test) between dimorphic seeds at the same concentration of $\mathrm{NaCl}$ or $\mathrm{Na}_{2} \mathrm{SO}_{4}$.

Li et al., 2016; Zhang et al., 2020), our study is the first to test the difference of salt tolerance between seeds and seedlings, and the interactions of light and temperature on germination of dimorphic seeds of S. salsa. Our study shows that dimorphic seeds have differential germination responses to light and temperature conditions. Brown seeds are more tolerant to salinity than black seeds during germination and seedling growth. $\mathrm{Na}_{2} \mathrm{SO}_{4}$ is more harmful to the germinating seeds than $\mathrm{NaCl}$. The results indicate that though brown seeds can germinate in high salt concentration, seedlings grown from them are damaged. Furthermore, recovery germination is an important strategy for black seeds after salt stress release.

Light did not affect germination percentages of brown seeds of $S$. salsa under different temperature regimes, however significantly improve germination of black seeds. The results suggest that black seeds of $S$. salsa require light to reach high 
TABLE 6 | Radicle tolerance index of $\mathrm{S}$. salsa seedlings grown from dimorphic seeds treated with different concentration of $\mathrm{NaCl}_{3}$ or $\mathrm{Na}_{2} \mathrm{SO}_{4}$.

\begin{tabular}{|c|c|c|c|c|}
\hline \multirow[t]{2}{*}{ Concentration (mM) } & \multicolumn{2}{|c|}{$\mathrm{NaCl}$} & \multicolumn{2}{|c|}{$\mathrm{Na}_{2} \mathrm{SO}_{4}$} \\
\hline & Seedlings from brown seeds & Seedlings from black seeds & Seedlings from brown seeds & Seedlings from black seeds \\
\hline 0 & $100.0 \pm 9.0 A a$ & $100.0 \pm 5.4 \mathrm{Aa}$ & $100.0 \pm 9.1 \mathrm{Aa}$ & $100.0 \pm 8.7 \mathrm{Aa}$ \\
\hline 50 & $82.2 \pm 6.0 A a b$ & $79.2 \pm 9.0 A b$ & $84.5 \pm 10.2 A a$ & $84.2 \pm 8.3 A a$ \\
\hline 100 & $72.2 \pm 4.2 A b c$ & $60.9 \pm 1.8 B C$ & $57.0 \pm 6.9 A b$ & $51.2 \pm 4.7 A b$ \\
\hline 200 & $62.0 \pm 5.0 A b c$ & $55.2 \pm 2.4 A c d$ & $48.3 \pm 2.6 A b c$ & $31.3 \pm 1.3 B c$ \\
\hline 300 & $58.1 \pm 4.5 A c d$ & $54.4 \pm 2.9 A c d$ & $41.8 \pm 1.2 A b c$ & $28.2 \pm 0.8 B c$ \\
\hline 400 & $50.2 \pm 4.0 A c d$ & $41.9 \pm 1.2 A d e$ & $36.2 \pm 1.6 \mathrm{Abcd}$ & $27.4 \pm 0.7 B c$ \\
\hline 600 & $39.1 \pm 3.7$ Ade & $34.1 \pm 1.4 A e$ & $31.0 \pm 0.9 A c d$ & $21.2 \pm 0.8 B c$ \\
\hline 800 & $39.1 \pm 4.0$ Ade & $26.5 \pm 1.0 B e$ & $27.9 \pm 0.8 A c d$ & $0.0 \pm 0.0 B d$ \\
\hline 1000 & $26.4 \pm 1.7 A e$ & $0.0 \pm 0.0 B f$ & $17.5 \pm 3.1$ Ade & $0.0 \pm 0.0 B d$ \\
\hline 1200 & $18.7 \pm 3.3 \mathrm{Ae}$ & $0.0 \pm 0.0 B f$ & $1.4 \pm 1.4 A e$ & $0.0 \pm 0.0 A d$ \\
\hline
\end{tabular}

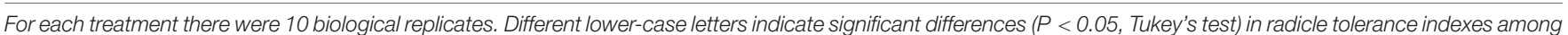

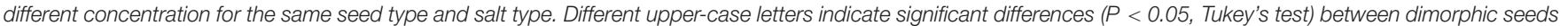
at the same concentration of $\mathrm{NaCl}$ or $\mathrm{Na}_{2} \mathrm{SO}_{4}$.

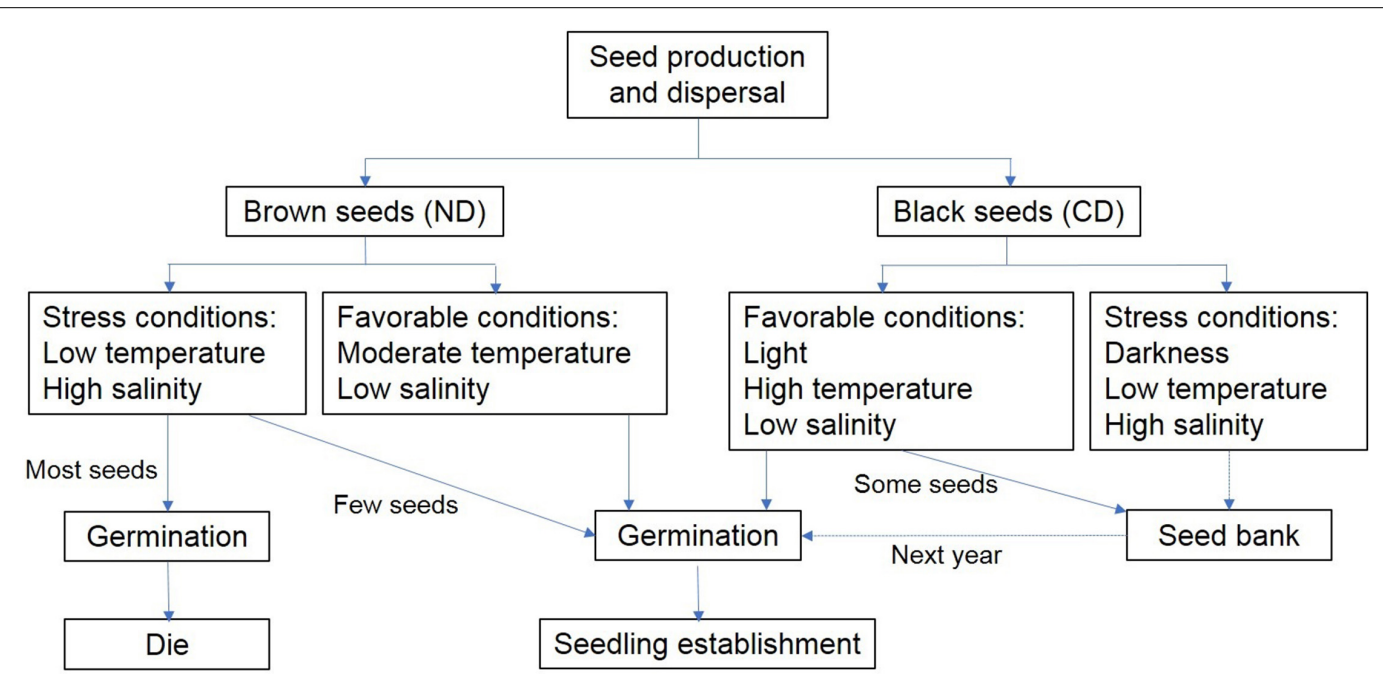

FIGURE 8 | Conceptual model of dynamics of germination and seedling growth of dimorphic seeds of $S$. salsa.

germination percentages, and more sensitive to light than brown seeds. The differential responses of dimorphic seeds to light are also reported in S. aralocaspica after cold stratification (Wang et al., 2017). Germination of brown seeds of S. aralocaspica was not affected by light conditions, however germination of cold-stratified black seeds was improved by light. The light requirement for germination of dormant seeds might be fulfilled by a period of cold stratification or high incubation temperature (Wang et al., 2008; Baskin and Baskin, 2014). Light requirement for germination is also reported in other heteromorphic seeds. Both central and peripheral achenes of Bidens pilosa had higher germination percentages in light condition than in darkness (Zhang et al., 2019).

Temperature is an important environmental factor and differentially regulates germination of dimorphic seeds of S. salsa (Li et al., 2008). Brown seeds could germinate to high percentages $(75 \%)$ in all of tested temperature regimes. This indicates that temperature is not a limiting factor for germination of brown seeds from spring to autumn and water conditions in the field might be a crucial factor. However, germination percentages of black seeds in light gradually increased from $17 \%$ at $5: 15^{\circ} \mathrm{C}$ to $95 \%$ at $20: 35^{\circ} \mathrm{C}$, and in darkness increased from $0 \%$ at $5: 15^{\circ} \mathrm{C}$ to $78 \%$ at $15: 30^{\circ} \mathrm{C}$. Our results show that germination of black seeds reach the highest at high temperature in light. The result reveals that black seeds of $S$. salsa have conditional dormancy and high temperature can decrease the limitation of dormancy during germination.

Salinity have different effects on germination and recovery of dimorphic seeds of $S$. salsa. Although germination percentages of dimorphic seeds decreased with the increase of salinity, brown seeds had higher salt tolerance than black seeds. At $600 \mathrm{mM} \mathrm{NaCl}$, brown seeds germinated to $77.6 \%$, but black seeds germinated to $46.4 \%$. This might be due to the difference in antioxidant ability between dimorphic seeds (Nisar et al., 2019b). Ungerminated seeds under high salinity stress regerminated 
when transferred to deionized water, especially for black seeds. The germination recovery percentage of black seeds gradually increased with the increase of pretreated salinity. This reveals that high salt pretreatment just temporally inhibits the germination of black seeds. This phenomenon has also been reported in many halophytes (Wang et al., 2008; Cao et al., 2012). For example, Limonium tabernense seeds have relatively low germination under $400 \mathrm{mM} \mathrm{NaCl}$, and ungerminated seeds have high germination recovery percentage $(>80 \%)$ when transferred to distilled water (Fernández et al., 2016). Furthermore, $\mathrm{Na}_{2} \mathrm{SO}_{4}$ had a stronger inhibitory effect on seed germination of S. salsa than $\mathrm{NaCl}$ at the same concentration. A previous study also shows that germination inhibition of $S$. salsa is in the following order: $\mathrm{Na}_{2} \mathrm{SO}_{4}>\mathrm{Na}_{2} \mathrm{CO}_{3}>\mathrm{NaCl}$ (Duan et al., 2007). However, seedling growth rate of Haloxylon ammodendron was higher in treatment with $\mathrm{Na}_{2} \mathrm{SO}_{4}$ than in iso-osmotic treatment with $\mathrm{NaCl}$. All radicles of Kalidium caspicum die before their length exceeded $5 \mathrm{~mm}$ in $-0.8 \mathrm{MPa} \mathrm{NaCl}$ solution, but $95 \%$ of the emerging radicles survives beyond $5 \mathrm{~mm}$ in the iso-osmotic PEG treatment. These results indicate that we need to carry out iso-osmotic experiment on seed germination and seedling growth of $S$. salsa in future research.

Shoot and radicle length of brown seeds of $S$. salsa are generally longer than that of black seeds under the same salinity. Maybe this is because brown seeds are heavier, and germinate earlier than black seeds (Song et al., 2008). Furthermore, brown seeds had higher radicle and shoot tolerance indexes than black seeds at high salinity. However, seedlings grown from brown seeds are damaged in high salt solutions. This strategy is a highrisk strategy (Venable, 1985; Imbert, 2002; Liu et al., 2018). In contrast, seedlings grown from black seeds had low radicle and shoot tolerance indexes. This can protect seedlings from black seeds against salt stress. Seedlings grown from black seeds of $S$. salsa emerge after the soil salt concentration decreases in the field. This strategy is a low-risk strategy. Dimorphic seeds and seedlings of $S$. salsa take advantage of this bet-hedging strategy in harsh saline habitats.

Based on the pattern of germination of dimorphic seeds and seedling growth of $S$. salsa, we propose a conceptual model for their dynamics (Figure 8). Brown seeds are non-dormant and can germinate under high-stress conditions. However, high soil salinity leads to dramatic damage of seedlings grown from brown seeds. Early germination may also give plants a selective advantage (Gutterman, 2002). Black seeds perform differently from brown seeds. They have non-deep physiological dormancy when mature in fall, and become non-dormant after exposure to the cold temperature during early winter and early spring of next year. Then the state of black seeds are changed between non-dormant and conditionally dormant in the soil seedbank. In

\section{REFERENCES}

Baiketuerhan, Y., Wu, R., Tielihan, N., Zhao, W., Chen, X., and Chen, J. (2019). Resource distribution and actuality of ancient trees in Wuerhe Kelamayi, Xinjiang. Chin Wild Plant Resour. 38, 66-72. (in Chinese with English abstract).

Baskin, C. C., and Baskin, J. M. (2014). Seeds: Ecology, Biogeography, and Evolution of Dormancy and Germination. San Diego, CA: Academic Press. spring, low temperature and high salinity lead to low germination of black seeds, especially when exposure to the light. High precipitation in summer decreases soil salinity. High temperature and low salinity might lead to high germination of black seeds when in the shallow soil layer. Thus, seedlings grown from black seeds could avoid the salt damage. At the end of growing season, ungerminated seeds might enter the persistent soil seed bank. This bet-hedging strategy protects $S$. salsa from unpredictable disaster and maintain the population growth.

\section{CONCLUSION}

In summary, the results indicate that dimorphic seeds of S. salsa have differential responses to light, temperature, and salinity. Light, temperature, and salinity are important environmental factors that regulating germination of black seeds. Brown seeds have high germination percentage and velocity in a wide range of environmental conditions. Seedlings of $S$. salsa are more sensitive than germinating seeds to the same salt concentration. Indexes of radicle can be used as an effective indicator to evaluate salt tolerance of halophytes. By using the bet-hedging strategy of dimorphic seeds, halophyte $S$. salsa can successfully adapt to the harsh saline deserts.

\section{DATA AVAILABILITY STATEMENT}

The raw data supporting the conclusions of this article will be made available by the authors, without undue reservation.

\section{AUTHOR CONTRIBUTIONS}

LW and JM contributed to the conception and design of the study. HZ, MH, and LJ collected the data. HZ, HM, LJ, ZZ, JM, and LW wrote the manuscript. HZ, MH, HM, LJ, ZZ, JM, and LW reviewed the manuscript. All authors have read and approved the final manuscript.

\section{FUNDING}

This work was funded by the State Key Laboratory of Desert and Oasis Ecology, Xinjiang Institute of Ecology and Geography, Chinese Academy of Sciences (G2018-02-04), the National Key Research and Development Program of China (2018YFE0207200), and the Foundation for Western Young Scholars, Chinese Academy of Sciences (2017-XBQNXZ-A-001).

Bhatt, A., Gairola, S., Carón, M. M., Santo, A., Murru, V., El-Keblawy, A., et al. (2020). Effects of light, temperature, salinity, and maternal habitat on seed germination of Aeluropus lagopoides (Poaceae): an economically important halophyte of arid Arabian deserts. Botany 98, 117-125. doi: 10.1139/cjb-20190096

Cao, D., Baskin, C. C., Baskin, J. M., Yang, F., and Huang, Z. (2012). Comparison of germination and seed bank dynamics of dimorphic seeds of the cold desert 
halophyte Suaeda corniculata subsp. mongolica. Ann. Bot. 110, 1545-1558. doi: $10.1093 / \mathrm{aob} / \mathrm{mcs} 205$

Duan, D., Li, W., Liu, X., Ouyang, H., and An, P. (2007). Seed germination and seedling growth of Suaeda salsa under salt stress. Ann. Bot. Fenn. 44, 161-169.

Fenner, M., and Thompson, K. (2005). The Ecology of Seeds. Cambridge, MA: Cambridge University Press.

Fernández, I. C. D., Luque, E. G., Mercado, F. G., and Pedrosa, W. (2016). Influence of temperature and salinity on the germination of Limonium tabernense Erben from Tabernas Desert (Almería, SE Spain). Flora 218, 68-74. doi: 10.1016/j. flora.2015.12.001

Gao, R., Wei, X., He, Z., Zhao, R., Wang, K., Yang, X., et al. (2018). Soil salt and $\mathrm{NaCl}$ have different effects on seed germination of the halophyte Suaeda salsa. J. Plant Nutr. Soil Sci. 181, 488-497. doi: 10.1002/jpln.201700544

Gul, B., Ansari, R., Flowers, T. J., and Khan, M. A. (2013). Germination strategies of halophyte seeds under salinity. Environ. Exp. Bot. 92, 4-18. doi: 10.1016/j. envexpbot.2012.11.006

Gutterman, Y. (2002). Survival Strategies of Annual Desert Plants. Berlin: SpringerVerlag.

Imbert, E. (2002). Ecological consequences and ontogeny of seed heteromorphism. Perspect. Plant Ecol. Evol. Syst. 5, 13-36. doi: 10.1078/1433-8319-00021

Khan, M. A., Gul, B., and Weber, D. J. (2001). Germination of dimorphic seeds of Suaeda moquinii under high salinity stress. Aust. J. Bot. 49, 185-192. doi: $10.1071 /$ bt00020

Li, W., An, P., and Liu, X. (2008). Effect of storage, stratification, temperature and gibberellins on germination of dimorphic seeds of Suaeda salsa under saline conditions. Seed Sci. Technol. 36, 122-132. doi: 10.15258/sst.2008. 36.1 .13

Li, W., Liu, X., Khan, M. A., and Yamaguchi, S. (2005). The effect of plant growth regulators, nitric oxide, nitrate, nitrite and light on the germination of dimorphic seeds of Suaeda salsa under saline conditions. J. Plant Res. 118, 207-214. doi: 10.1007/s10265-005-0212-8

Li, W., Yamaguchi, S., Khan, M. A., An, P., Liu, X., and Tran, L. P. (2016). Roles of gibberellins and abscisic acid in regulating germination of Suaeda salsa dimorphic seeds under salt stress. Front. Plant Sci. 6:1235. doi: 10.3389/fpls. 2015.01235

Liu, R., Wang, L., Tanveer, M., and Song, J. (2018). Seed heteromorphism: an important adaptation of halophytes for habitat heterogeneity. Front. Plant Sci. 9:1515. doi: 10.3389/fpls.2018.01515

Nisar, F., Gul, B., Khan, M. A., and Hameed, A. (2019a). Germination and recovery responses of heteromorphic seeds of two co-occurring Arthrocnemum species to salinity, temperature and light. S. Afr. J. Bot. 121, 143-151. doi: 10.1016/j.sajb. 2018.10.035

Nisar, F., Gul, B., Khan, M. A., and Hameed, A. (2019b). Heteromorphic seeds of coastal halophytes Arthrocnemum macrostachyum and A. indicum display differential patterns of hydrogen peroxide accumulation, lipid peroxidation and antioxidant activities under increasing salinity. Plant Physiol. Biochem. 144, 58-63. doi: 10.1016/j.plaphy.2019.09.031

Pons, T. L. (2014). "Light-mediated germination," in Seeds: The Ecology of Regeneration in Plant Communities, 3rd Edn, ed. R. S. Gallagher (Wallingford: CABI Publishing).

Qu, X. X., Huang, Z. Y., Baskin, J. M., and Baskin, C. C. (2008). Effect of temperature, light and salinity on seed germination and radicle growth of the geographically widespread halophyte shrub Halocnemum strobilaceum. Ann. Bot. 101, 293-299. doi: 10.1093/aob/mcm047

Rasheed, A., Hameed, A., Gul, B., and Khan, M. A. (2019). Perianth and abiotic factors regulate seed germination of Haloxylon stocksii-A cash crop candidate for degraded saline lands. Land Degrad. Dev. 30, 1468-1478. doi: 10.1002/ldr. 3334

Shang, C., Wang, L., Tian, C., and Song, J. (2020). Heavy metal tolerance and potential for remediation of heavy metal-contaminated saline soils for the euhalophyte Suaeda salsa. Plant Signal. Behav. 15:e1805902. doi: 10.1080/ 15592324.2020.1805902

Song, J., Fan, H., Zhao, Y., Jia, Y., Du, X., and Wang, B. (2008). Effect of salinity on germination, seedling emergence, seedling growth and ion accumulation of a euhalophyte Suaeda salsa in an intertidal zone and on saline inland. Aquat. Bot. 88, 331-337. doi: 10.1016/j.aquabot.2007.11.004

Song, J., Shi, W., Liu, R., Xu, Y., Sui, N., Zhou, J., et al. (2017). The role of the seed coat in adaptation of dimorphic seeds of the euhalophyte Suaeda salsa to salinity. Plant Spec. Biol. 32, 107-114. doi: 10.1111/1442-1984.12132

Song, J., and Wang, B. (2015). Using euhalophytes to understand salt tolerance and to develop saline agriculture: Suaeda salsa as a promising model. Ann. Bot. 115, 541-553. doi: 10.1093/aob/mcu194

Venable, D. L. (1985). The evolutionary ecology of seed heteromorphism. Am. Nat. 126, 577-595. doi: 10.1086/284440

Wang, H. L., Tian, C. Y., and Wang, L. (2017). Germination of dimorphic seeds of Suaeda aralocaspica in response to light and salinity conditions during and after cold stratification. PeerJ 5:e3671. doi: 10.7717/peerj.3671

Wang, L., Huang, Z., Baskin, C. C., Baskin, J. M., and Dong, M. (2008). Germination of dimorphic seeds of the desert annual halophyte Suaeda aralocaspica (Chenopodiaceae), a C4 Plant without Kranz Anatomy. Ann. Bot. 102, 757-769. doi: 10.1093/aob/mcn 158

Wang, L., Wang, X., Jiang, L., Zhang, K., Tanveer, M., Tian, C., et al. (2020). Reclamation of saline soil by planting annual euhalophyte Suaeda salsa with drip irrigation: a three-year field experiment in arid northwestern China. Ecol. Eng. 159:106090. doi: 10.1016/j.ecoleng.2020.106090

Xi, J. B., Zhang, F. S., and Tian, C. Y. (2006). Halophytes in Xinjiang. Beijing: Science Press.

Yang, A., and Chen, Z. (2020). The control of seed dormancy and germination by temperature, light and nitrate. Bot. Rev. 86, 39-75. doi: 10.1007/s12229-02009220-4

Yang, L., Liu, S., and Lin, R. (2020). The role of light in regulating seed dormancy and germination. J. Integr. Plant Biol. 62, 1310-1326. doi: 10.1111/jipb.13001

Zhang, H., Jiang, L., Tanveer, M., Ma, J., Zhao, Z., and Wang, L. (2020). Indexes of radicle are sensitive and effective for assessing copper and zinc tolerance in germinating seeds of Suaeda salsa. Agriculture 10:445. doi: 10.3390/ agriculture10100445

Zhang, H., Tian, Y., Guan, B., Zhou, D., Sun, Z., and Baskin, C. C. (2018). The best salt solution parameter to describe seed/seedling responses to saline and sodic salts. Plant Soil 426, 313-325. doi: 10.1007/s11104-018-3623-8

Zhang, K., Yao, L., Zhang, Y., and Tao, J. (2019). Achene heteromorphism in Bidens pilosa (Asteraceae) differences in germination and possible adaptive significance. AoB Plants 11, 1-8. doi: 10.1093/aobpla/plz026

Zhao, K. F. (1991). Desalinization of saline soils by Suaeda salsa. Plant Soil 135, 303-305. doi: 10.1007/BF00010921

Zhao, Y., Song, S. Q., and Yin, S. H. (2004). Difference of behavior of germination and growth of two types of Suaeda salsa seeds. Seed Sci. Technol. 32, 739-748. doi: 10.15258/sst.2004.32.3.09

Zhu, G., Mosyakin, S. L., and Clemants, S. E. (2003). “Chenopodiaceae," in Flora of China, eds Z. Wu \& P. H. Raven (St. Louis: Science Press), 389-394.

Conflict of Interest: The authors declare that the research was conducted in the absence of any commercial or financial relationships that could be construed as a potential conflict of interest.

Copyright (c) 2021 Zhang, Hu, Ma, Jiang, Zhao, Ma and Wang. This is an open-access article distributed under the terms of the Creative Commons Attribution License (CC BY). The use, distribution or reproduction in other forums is permitted, provided the original author(s) and the copyright owner(s) are credited and that the original publication in this journal is cited, in accordance with accepted academic practice. No use, distribution or reproduction is permitted which does not comply with these terms. 